\title{
Pre-Transplantation Serum Parathyroid Hormone Influences the Number of Mobilized CD34+ Hematopoietic Stem Cells in Autologous Hematopoietic Stem Cell Transplantation
}

\author{
Abdolhamed Kian ${ }^{1}$, Sayeh Parkhideh*1, Haniyeh Ghaffari Nazari ${ }^{1}$, \\ Maryam Nikoonezhad ${ }^{1}$, Arsalan Jalili ${ }^{1}$, Shaghayegh Shahsavan ${ }^{1}$, Abbas Hajifathali ${ }^{1}$
}

\begin{abstract}
Background: Parathyroid hormone (PTH) is a calcium homeostasis regulator and can affect bone marrow niche. PTH leads to the bone marrow stem cell niche expansion as well as the induction of stem cell mobilization from the bone marrow into peripheral blood. In this study, we evaluated the association between pre- transplantation serum PTH levels and the number of circulating CD34+ cells along with the platelets/white blood cells (Plt/WBC) engraftment in patients who underwent autologous Hematopoietic Stem Cell Transplantation.

Methods: Subjects for the study were 100 patients who received autologous hematopoietic stem cell transplantation (auto-HSCT), retrospectively. Serum levels of PTH, calcium, phosphorus, and alkaline phosphatase were measured before mobilization. Their impacts were measured on the number of mobilized CD34+ hematopoietic stem cells, and Plt/WBC engraftment.

Results: High levels of serum PTH (> $63.10 \mathrm{pg} / \mathrm{mL}$ ) was significantly associated with higher number of CD34+ cells in peripheral blood after granulocyte- colony stimulating factor (G-CSF)-induced mobilization $(p=0.079 *)$. Serum calcium at low levels were associated with higher number of circulating CD34+ cells post mobilization. Pre- transplantation serum levels of phosphorus and alkaline phosphatase on CD34+ numbers were not statistically significant. Serum Plt/WBC engraftment was not improved in presence of high levels of serum PTH.

Conclusions: We suggested that serum PTH levels before transplantation could be influential in raising the number of circulating CD34+ hematopoietic stem cell after mobilization.
\end{abstract}

Keywords: Auto-HSCT, CD34+ Cell, Pre- transplant PTH.

\section{Introduction}

Hematopoietic Stem Cell Transplantation (HSCT) is an important and often life-saving treatment for many hematological malignancies. Hematopoietic stem cell transplantation categorized to autologous (autoHSCT) and allogeneic (allo-HSCT) based on stem cells source. Peripheral blood stem cells (PBMCs) are widely used and replaced bone marrow (BM) as source of stem cells for both autologous and allogeneic HSCT (1). Peripheral blood stem cells (PBSCs) isolation is a less invasive and engraft more quickly than BMderived stem cells (2). Peripheral blood hematopoietic stem cells (HSCs) are found in low numbers, requiring mobilize stimulation agents for adequate HSC collection. The dose of injected CD34 cells is an important determinant of neutrophil and platelet transplantation that is dependent on the success of stem cell mobilization (3). Granulocyte- colony stimulating factor is the very usual agent for HSC mobilization which is commonly prescribed to 
obtain the optimal number of CD34+ cells used in HSCT (4). Nevertheless, failure of mobilization is reported in $5 \%$ to $30 \%$ of patients and healthy donors (5). In patients with multiple myeloma and non-Hodgkin lymphoma (NHL) who tend to be a heavily pretreated group, mobilization with G-CSF alone may lead to mobilization failure (4). Bone marrow disease, genetics, prior treatment, and age are factors influencing CD34+ cells mobilization (5). The effect of other agents have been considered with G-CSF in mobilization for improving the stem cell yield and reducing the number of apheresis sessions (4). During human development, stem cells establish in specific anatomic locations called niche. Niche components determine stem cell numbers as well as functions. Osteoblasts and calcium sensing receptor, expressed by HSC, are niche components affecting HSC numbers (6). Parathyroid hormone (PTH) regulates serum calcium through its effects on bone, kidney, and the intestine. Parathyroid hormone has also been influenced in bone marrow environment which expands the stem cell niche (7). Niche resident osteoblasts are activated by PTH or PTH-related protein and produce hematopoietic growth factors (8). Therefore, PTH concentration as a factor that affect osteoblast function may play a role in stem cell mobilization and engraftment.

The stem cell mobilization failure requires further investigation and finding solutions with minimal complications in the patients undergoing HSCT. Since previous studies demonstrated the PTH proliferation effect in the bone marrow and mobilization of stem cells to peripheral blood, this study assayed the association between the serum levels of endogenous PTH and mobilized hematopoietic stem cell in the patients who received autologous HSCT (auto-HSCT).

\section{Materials and Methods \\ Ethical approval}

Ethical approval was waived by the local Ethics Committee of University (IR.SBMU.REC.1398.118). An in view of the retrospective nature of the study and all the procedures being performed were part of the routine care.

All persons gave their informed consent prior to their inclusion in the study.

\section{HSCT procedure}

One hundred patients who underwent autoHSCT were entered this retrospective study. Patients' demographic is summarized in Table 1.

The CD34+ stem cells mobilization and collection process were as follows: Filgrastim (recombinant human G-CSF) at dosage of 5-10 $\mu \mathrm{g} / \mathrm{kg} /$ day was administered subcutaneously for 4-5 consecutive days for mobilizing stem cell from bone marrow into peripheral blood. Then their peripheral blood stem cells (PBSCs) were isolated by apheresis (Terumo BCT, Lakewood, $\mathrm{CO}$ ). In poor mobilizer patients, Plerixafor (an immunostimulant used to mobilize hematopoietic stem cells) at a dosage of $24 \mathrm{mg}$ was administered 12 hours before apheresis.

The patients received conditioning regimens and supportive care that were defined in our previous study (9). Briefly, conditioning regimen in patients with lymphoma, Hodgkin's disease (HD), and non-Hodgkin's lymphoma (NHL), were prescribed comprised of Cytarabine $\left(300 \mathrm{mg} / \mathrm{m}^{2}\right.$ for 2 days, IV), Etoposide $\left(300 \mathrm{mg} / \mathrm{m}^{2}\right.$ for 2 days, IV) and Melphalan $\left(140 \mathrm{mg} / \mathrm{m}^{2}\right.$ for 1 day, IV). In some patients $100 \mathrm{mg} / \mathrm{m}^{2}$ of CCNU (1-2-chloroethyl3-cyclohexyl-1-nitrosourea) for 2 days (oral) was added to this combination. Patients with multiple myeloma (MM) received Melphalan at dosage of $200 \mathrm{mg} / \mathrm{m}^{2}$ for 1 day as conditioning regimen. Following conditioning regimens, PBSCs transplantation was performed by an average of $3.2 \times 10^{6} \mathrm{CD} 34+$ and $330 \times 10^{6} \mathrm{CD} 3+$ cells/kg (10).

After HSCT, the patients were hospitalized, and hematopoietic engraftment was monitored in the BMT clinic. The platelet and white blood cell (WBC) engraftment were defined, respectively as the platelet count $\geq 20000 / \mu \mathrm{L}$ for 3 continuous days without platelet transfusion and WBC count $\geq 1000 / \mu \mathrm{L}$ in 3 consecutive days without the blood product transfusion (10). 
Table1. The descriptive statistics of the patients under study ( $n=94)$.

\begin{tabular}{|c|c|c|}
\hline Variables & Subgroup & $(\%) /$ mean \pm SD \\
\hline \multirow{2}{*}{ Weight } & - & $75.85 \pm 13.98$ \\
\hline & Missing & $7(7.4)$ \\
\hline \multirow{2}{*}{ Age } & - & $46.59 \pm 12.87$ \\
\hline & Missing & $0(0.0)$ \\
\hline \multirow{3}{*}{ Gender } & Male & $53(56.4)$ \\
\hline & Female & $41(43.6)$ \\
\hline & Missing & $0(0.0)$ \\
\hline \multirow{5}{*}{ Diagnosed disease } & MM & $48(51.1)$ \\
\hline & $\mathrm{HD}$ & $31(33.0)$ \\
\hline & NHD & $8(8.5)$ \\
\hline & Unclassified & $6(6.4)$ \\
\hline & Missing & $1(1.1)$ \\
\hline \multirow{5}{*}{$\begin{array}{l}\text { Conditioning } \\
\text { Regimen }\end{array}$} & Melphalan+Cytarabine+Etoposid+CCNU & $43(45.7)$ \\
\hline & Melphalan+Cytarabine+Etoposid & $13(13.8)$ \\
\hline & Melphalan & $10(10.6)$ \\
\hline & Unclassified & $17(18.1)$ \\
\hline & Missing & $11(11.7)$ \\
\hline \multirow{3}{*}{ G-CSF type } & Filgrastim & $53(56.4)$ \\
\hline & Filgrastim+ Plerixafor & $41(43.6)$ \\
\hline & Missing & $0(0.0)$ \\
\hline \multirow{2}{*}{ G-CSF } & - & $12.95 \pm 3.30$ \\
\hline & Missing & $9(9.6)$ \\
\hline \multirow{5}{*}{$\begin{array}{l}\text { Parathyroid } \\
\text { hormone }\end{array}$} & Quartile1 & $24(25.5)$ \\
\hline & Quartile 2 & $23(24.5)$ \\
\hline & Quartile 3 & $24(25.5)$ \\
\hline & Quartile 4 & $23(24.5)$ \\
\hline & Missing & $0(0.0)$ \\
\hline \multirow{4}{*}{ Phosphorus } & $<2.5$ & $8(8.5)$ \\
\hline & $2.5-5$ & $75(79.8)$ \\
\hline & $>5$ & $11(11.7)$ \\
\hline & Missing & $0(0.0)$ \\
\hline \multirow{4}{*}{ Calcium } & $<8.3$ & $11(11.7)$ \\
\hline & $8.3-10.3$ & $79(84.0)$ \\
\hline & $>10.3$ & $4(4.3)$ \\
\hline & Missing & $0(0.0)$ \\
\hline \multirow{3}{*}{$\begin{array}{l}\text { Alkaline } \\
\text { Phosphatase }\end{array}$} & $<270$ & $84(89.4)$ \\
\hline & $>270$ & $10(10.6)$ \\
\hline & Missing & $0(0.0)$ \\
\hline $\begin{array}{l}\text { Neutrophil } \\
\text { Engraftment }\end{array}$ & - & $59(62.8)$ \\
\hline PLT Engraftment & - & $51(54.3)$ \\
\hline
\end{tabular}

SD, Standard Deviation; MM, Multiple Myeloma; HD, Hodgkin disease; NHD, Non-Hodgkin disease; G-CSF, Granulocyte colony-stimulating factor; PLT, Platelet. 


\section{Laboratory analysis}

The number of CD34+ cells in peripheral blood were analyzed by flow cytometry (Attune NxT Acoustic Focusing Cytometer, Thermo Fisher Scientific Inc, USA) Anti human CD34-PE antibody (Beckman Coulter, USA) were used to identify hematopoietic stem cells. Prior to mobilization serum concentrations of $\mathrm{Ca}$ (normal range: 8.3-10.5 $\mathrm{mg} / \mathrm{dl}$ ), $\mathrm{P}$ (normal range: $2.5-5 \mathrm{mg} / \mathrm{dl}$ ), ALP (normal range: 50-160 U/L) and PTH (normal range $11-67 \mathrm{pg} / \mathrm{ml}$ ) were measured by routine automated methods.

\section{Statistical Method}

The patients' characteristics were presented as frequency $(\%)$ or mean \pm standard deviation. The weight, age, gender, diagnosed disease, G-CSF, G-CSF type, serum PTH, phosphorus, calcium and alkaline phosphatase were all included in the analysis as risk factors for predicting the hematopoietic stem cell mobilization. Serum PTH was categorized into quartiles. (Q1: $<29$, Q2:29.1-42.75, Q3: 42.76-63.10, Q4:> 63.10). A linear regression model was utilized for the univariate and multiple analysis with CD34 as the outcome of interest. Moreover, the association of risk factors including PTH, phosphorus, calcium and alkaline phosphatase with neutrophil and platelet engraftment time as outcomes of interest were explored through a univariate Cox proportional hazard model. The frequency of risk factors by PTH was also conducted through a cross tabulation. All of the analyses were carried out using SPSS version 19.0 (SPSS Inc., Chicago, IL, USA) and R programming language version 3.5.2. The significance level was set at 0.75 for univariate and 0.90 for multiple regression model.

\section{Results}

The descriptive statistics is shown in Table 1 . The analysis was conducted on 94 patients with hematological disorders with a mean age of $46.59 \pm 12.87$ years. About half of the patients $53(56.4 \%)$ were males and half of them 41 $(43.6 \%)$ were females. The most diagnosed disease was $\mathrm{MM}$ comprising $48(51.1 \%)$ of all patients. Fifty-three $(56.4 \%)$ of the patients received Filgrastim and the rest of them received Filgrastim + Plerixafor. The majority of the patients had normal serum phosphorus levels. Eleven (11.7\%) patients had calcium levels lower than $8.3(\mathrm{mg} / \mathrm{dL})$. Higher alkaline phosphatase levels (> 270U/L) were observed in $10(10.6 \%)$ patients. When the outcome variable was neutrophil engraftment, 59 $(62.8 \%)$ had engraftment and when the outcome was PLT engraftment, 51 (54.3\%) had engraftment.

\section{Association of risk factors with Hematopoietic Stem Cell Mobilization}

We performed a univariate linear regression analysis to study the risk factors on hematopoietic stem cell mobilization. The risk factors including conditioning regimen, PTH and calcium were found to be significant $(\mathrm{p}=$ $0.016 ; \mathrm{p}=0.079 ; \mathrm{p}=0.096$, respectively) and were entered the multiple models. The results are demonstrated in Table 2. As shown, the highest quartile of PTH level was significantly associated with $\mathrm{CD} 34$ in which for $\mathrm{PTH}>63.10$ $(\mathrm{pg} / \mathrm{mL})$ in comparison with the PTH (29.142.75) ( $\mathrm{pg} / \mathrm{mL})$, the CD34 positive cell was expected to increase by $24.09 \%$ (90\% CI: (6.60, 41.56); $\mathrm{p}$-value $=0.079)$. Calcium level lower than $8.3(\mathrm{mg} / \mathrm{dL})$, was expected to increase CD34 expression by $24.81 \%$ compared to the normal level (8.3-10.3) (90\% CI: (5.78, 43.83); $\mathrm{p}$-value $=0.096)$. Additionally, among the conditioning regimens, Melphalan+Cytarabine + Etoposid+CCNU compared to the unclassified group was expected to increase the CD34 expression by $39.12 \%$ (90\% CI: $(18.79,59.44)$; $\mathrm{p}$-value $=0.016$ ).

\section{Association of risk factors with PLT and WBC engraftment}

The neutrophil and PLT engraftment using Cox proportional hazards model is illustrated in Table 3. The time of PLT engraftment in patients with highest level of PTH was delayed by $61 \%$ compared to the second quartile of PTH $(p-v a l u e=0.035)$. The time of WBC engraftment in patients with highest 
level of PTH was delayed by $21 \%$ compared to the second quartile of PTH, which was not statistically significant $(p$-value $=0.600)$. There was a $38 \%$ improvement in PLT engraftment for those patients with calcium level lower that $8.3(\mathrm{mg} / \mathrm{dL})$ compared to the normal level (8.3-10.3), however it was not significant $\quad(p$-value $=0.460) . \quad$ Alkaline phosphatase enhanced the neutrophil engraftment by $20 \%$ which was statistically insignificant $(p$-value $=0.620)$.

Table 2. The multiple linear regression model for Hematopoietic Stem Cell Mobilization.

\begin{tabular}{llll}
\hline Variables & Estimate & SE $\mathbf{9 0 \%}$ CI) & p-Value \\
\hline Conditioning Regimen & & & \\
\hline $\begin{array}{l}\text { Melphalan + Cytarabine + Etoposid + } \\
\text { CCNU }\end{array}$ & 39.12 & $15.62(18.79,59.44)$ & $0.016^{*}$ \\
\hline Melphalan + Cytarabine + Etoposid & 13.56 & $15.13(-6.13,33.25)$ & 0.375 \\
\hline Melphalan & 10.61 & $12.43(-5.57,26.78)$ & 0.398 \\
\hline Unclassified $\left(\mathrm{RL}^{1}\right)$ & - & - & - \\
\hline PTH & & & \\
\hline Quartile 1 & 15.23 & $15.94(-5.51,35.97)$ & 0.344 \\
\hline Quartile 3 & 14.67 & $13.68(-3.13,32.47)$ & 0.289 \\
\hline Quartile 4 & 24.09 & $13.43(6.60,41.56)$ & $0.079^{*}$ \\
\hline Quartile 2 $\left(\mathrm{RL}^{1}\right)$ & - & - & - \\
\hline
\end{tabular}

Calcium

\begin{tabular}{llll}
\hline$<8.3$ & 24.81 & $14.62(5.78,43.83)$ & $0.096^{*}$ \\
\hline$>10.3$ & 10.31 & $26.07(-23.62,44.23)$ & 0.694 \\
\hline $8.3-10.3\left(\mathrm{RL}^{1}\right)$ & - & - & - \\
\hline
\end{tabular}

1. Reference level, $*$ Significant at 0.10

Table 3. Univariate Cox Regression Models for PLT and WBC engraftment time.

\begin{tabular}{|c|c|c|c|c|}
\hline & $\begin{array}{l}\text { HR (PLT } \\
\text { engraftment) }\end{array}$ & p-value & $\begin{array}{l}\text { HR (WBC } \\
\text { engraftment) }\end{array}$ & p-value \\
\hline \multicolumn{5}{|l|}{ PTH } \\
\hline Quartile 1 & 0.70 & 0.360 & 0.94 & 0.869 \\
\hline Quartile 3 & 0.94 & 0.871 & 0.92 & 0.836 \\
\hline Quartile 4 & 0.39 & 0.035 & 0.81 & 0.600 \\
\hline Quartile 2(RL $\left.{ }^{1}\right)$ & - & - & - & - \\
\hline \multicolumn{5}{|l|}{ Phosphorus } \\
\hline$<2.5$ & 1.16 & 0.729 & 1.01 & 0.982 \\
\hline$>5.0$ & 0.80 & 0.655 & 0.94 & 0.902 \\
\hline $2.5-5\left(\mathrm{RL}^{1}\right)$ & - & - & - & - \\
\hline \multicolumn{5}{|l|}{ Calcium } \\
\hline$<8.3$ & 1.38 & 0.460 & 1.03 & 0.936 \\
\hline$>10.3$ & 0.35 & 0.308 & 0.66 & 0.576 \\
\hline 8.3-10.3(RL $\left.{ }^{1}\right)$ & - & - & - & - \\
\hline \multicolumn{5}{|c|}{ Alkaline Phosphatase } \\
\hline$>270$ & 1.17 & 0.718 & 1.20 & 0.620 \\
\hline$<270\left(\mathrm{RL}^{1}\right)$ & - & - & - & - \\
\hline
\end{tabular}

1. Reference level, * Significant at 0.10 . 
Table 4 represents the frequency of PTH quartiles in different categories of calcium and G-CSF types. Nineteen patients $(24.4 \%)$ in the highest quartile of serum PTH had normal calcium levels and only 3 (25.0\%) subjects in the highest quartile of serum PTH had low calcium levels. Ten (18.9\%) patients presented with Filgrastim had the highest PTH levels and $6(14.9 \%)$ subjects who received Filgrastim+ Plerixafor had the lowest PTH levels.

Table 4. The association of Calcium and G-CSF type with PTH.

\begin{tabular}{|c|c|c|c|c|c|}
\hline \multirow{2}{*}{ Variable } & \multirow{2}{*}{ Subgroup } & \multicolumn{4}{|c|}{ PTH } \\
\hline & & Quartile1 & Quartile 2 & Quartile 3 & Quartile 4 \\
\hline \multirow{3}{*}{ Calcium } & $<8.3$ & $4(33.3)$ & $2(16.7)$ & $3(25.0)$ & $3(25.0)$ \\
\hline & $8.3-10.3$ & $19(24.4)$ & $20(25.6)$ & $20(25.6)$ & $19(24.4)$ \\
\hline & $>10.3$ & $1(25.0)$ & $1(25.0)$ & $1(25.0)$ & $1(25.0)$ \\
\hline \multirow{2}{*}{ G-CSF type } & Filgrastim & $18(34.0)$ & $13(24.5)$ & $12(22.6)$ & $10(18.9)$ \\
\hline & Filgrastim+ Plerixafor & $6(14.6)$ & $10(24.4)$ & $12(29.3)$ & 13(31.7) \\
\hline
\end{tabular}

1. Reference level, $*$ Significant at 0.10

\section{Discussion}

The number of CD34 + cells in peripheral blood stem cell transplantation (PBSCT) is considered to be associated with transplantation outcomes; including, engraftment, overall survival (OS), transplantation-related mortality (TRM), and GVHD (11). In this study we demonstrated that SPTH level was associated with the number of CD34 + hematopoietic stem cells in patients who underwent auto-HSCT. We pointed out that higher levels of pretransplantation $\mathrm{SPTH}$ which categorized as upper Quartile (Q3) and maximum value (> $63.10 \mathrm{pg} / \mathrm{ml}$ ) were tended towards higher frequency of CD34 + cell numbers in peripheral blood. As stated, pre-transplantation sPTH> $63.10 \mathrm{pg} / \mathrm{ml}$ was significantly associated with the elevated frequency of CD34 + number following mobilization, although it did not have a positive effect on $\mathrm{Plt} / \mathrm{WBC}$ engraftment improvement. Parathyroid hormone stimulation effect on regulating HSC has been assessed in experimental and clinical investigations and different mechanisms were suggested to explain this issue. Early report from Calvi et al. in 2003 revealed a relationship between PTH and HSC niche. They reported that PTH indirectly activate Notch pathway in HSC through the (upregulation of the Notch ligand jagged 1 on the resident osteoblast in BM niche (12). Another animal study suggested that PTHinduced mobilization is possibly associated with releasing endogenous G-CSF because endogenous G-CSF blockage decreased the number of circulating progenitor cells following PTH treatment (13). Pirih et al. also showed IL6 mediated the PTH regulating actions on hematopoietic cell expansion in concert with Flt3-L (14). In addition, $T$ cell dependent mechanism, T cell-produced Wnt10b, was reported as an involved mechanism in PTH effect on regulating HSC (15). There is limited clinical studies about the PTH effects in HSCT transplantation setting. The main investigation into PTH effect on HSC was conducted either exogenous PTH prescription or in patients with primary or secondary hyperparathyroidism with abnormal levels of serum PTH (16-18). As an illustration, Adams et al in the first preclinical mouse models, found that PTH administration for 5 weeks following 5 days G-CSF regimen increased the number of HSCs which can be mobilized by G-CSF into the peripheral blood and protected stem cell from repeated exposure to chemotherapeutic agents, as well as expanding stem cells in transplant recipients (19). Defined subpopulations of mobilized BMCs into peripheral blood were investigated in 22 patients with primary hyperparathyroidism (PHPT) who had high PTH serum levels $(67 \mathrm{pg} / \mathrm{ml})$ and 10 control by Brunner et al. They reported elevated circulating BMCs as well as upregulated serum levels of SDF-1 and VEGF in PHPT patients. Moreover, they found positive correlation between the number of circulating BMCs and serum levels of PTH (20). In a phase I trial, 20 
patients who experienced 1 or 2 unsuccessful mobilization received PTH in different dosages for 14 day plus Filgrastim for 4 days. Reaching the mobilization criteria (>5 CD34 + cells $/ \mu \mathrm{L})$ was observed in $47 \%$ and $40 \%$ of the patients who were candidates for auto-HSCT and met 1 or 2 unsuccessful mobilization, respectively. They suggested that the evaluation of longer treatment interval required addressing $\mathrm{PTH}$ activity on HSC (18). The same group conducted a phase II trial based on PTH administration post umbilical cord blood transplantation (UCBT) to enhance hematopoietic recovery in a low stem cell numbers clinical setting. The commercial human PTH 1-34 (Teriparatide) $100 \mu \mathrm{g} /$ day was administrated for days 1-28 of the study or until neutrophil engraftment. They did not find any evidence that PTH improved hematopoiesis and immune reconstitution. It has been suggested that different approaches may be more effective in hematopoiesis recovery and

\section{References}

1. Hatzimichael E, Tuthill M. Hematopoietic stem cell transplantation. Stem cells cloning. 2010;3:105-17.

2. Vellenga E, Van Agthoven M, Croockewit AJ, Verdonck LF, Wijermans PJ, van Oers MH, et al. Autologous peripheral blood stem cell transplantation in patients with relapsed lymphoma results in accelerated haematopoietic reconstitution, improved quality of life and cost reduction compared with bone marrow transplantation: the Hovon 22 study. $\mathrm{Br} \mathrm{J}$ Haematol. 2001;114(2):319-26.

3. Pecora AL. Impact of stem cell dose on hematopoietic recovery in autologous blood stem cell recipients. Bone Marrow Transplant. 1999;23(Suppl 2):S7-12.

4. Hopman RK, DiPersio JF. Advances in stem cell mobilization. Blood Rev. 2014;28(1):31-40.

5. To LB, Levesque JP, Herbert KE. How I treat patients who mobilize hematopoietic stem cells poorly. Blood. 2011;118(17):4530-40.

6. Ballen K. Targeting the stem cell niche: squeezing blood from bones. Bone Marrow Transplant. 2007;39(11):655-60. lashing the stem cells $(21,22)$. Although we did not conduct PTH therapy as an intervention in our patients like the Ballen's study, we pointed out that higher sPTH levels increased the number of CD34 + cells without influence on patients' outcomes similar to PTH administration. Serum PTH at upper quarters of normal range was accompanied by elevated count of CD34 + cells after mobilization. We suggest SPTH evaluation before mobilization and patients' treatment if they have low SPTH levels which might help obtaining a better CD34 + yield post mobilization.

\section{Acknowledgements}

The authors would like to thank of Hematopoietic Stem Cell Research Center and Taleghani Hospital, Shahid Beheshti University of Medical Sciences, Tehran, Iran for providing the possibility of doing the study and helpful assistance.

The authors declare no conflict of interest.

7. Ohishi M, Schipani E. PTH and stem cells. J Endocrinol Invest 2011;34(7):552-6.

8. Huber BC, Grabmaier U, Brunner S. Impact of parathyroid hormone on bone marrow-derived stem cell mobilization and migration. World $\mathbf{J}$ Stem Cells. 2014;6(5):637-643.

9. Parkhideh S, Chegeni R, Mehdizadeh M, Roshandel E, Tavakoli F, Hajifathali A. Effects of $\mathrm{ABO}$ incompatibility on the outcome of allogeneic hematopoietic stem cell transplantation. Transfus Apher Sci. 2020;59(2):102696.

10. Appelbaum FR, Forman SJ, Negrin RS, Blume KG. Thomas' hematopoietic cell transplantation: John Wiley \& Sons;2011.

11. Perez-Simon JA, Diez-Campelo Ma, Martino R, Sureda A, Caballero D, Canizo C, et al. Impact of CD34+ cell dose on the outcome of patients undergoing reduced-intensityconditioning allogeneic peripheral blood stem cell transplantation. Blood. 2003;102(3):110813.

12. Calvi L, Adams G, Weibrecht K, Weber JM, Olson DP, Knight MC, et al. Osteoblastic cells 
regulate the haematopoietic stem cell niche. Nature. 2003;425(6960):841-6.

13. Brunner S, Zaruba M-M, Huber B, David R, Vallaster M, Assmann G, et al. Parathyroid hormone effectively induces mobilization of progenitor cells without depletion of bone marrow. Exp hematol. 2008;36(9):1157-66.

14. Pirih FQ, Michalski MN, Cho SW, Koh AJ, Berry JE, Ghaname E, et al. Parathyroid hormone mediates hematopoietic cell expansion through interleukin-6. PloS one. 2010;5(10):e13657.

15. Li JY, Adams J, Calvi LM, Lane TF, DiPaolo $\mathrm{R}$, Weitzmann MN, et al. PTH expands short-term murine hemopoietic stem cells through $\mathrm{T}$ cells. Blood. 2012;120(22):4352-62.

16. Lomonte C, Derosa C, Vernaglione L, Casucci F, Losurdo N, Libutti P, et al. Serum parathyroid hormone and phosphate influence the levels of circulating CD34+ cells in uremia. $\mathbf{J}$ Nephrol. 2010;23(6):693-8.

17. Coppolino G, Bolignano D, De Paola L, Giulino C, Mannella A, Riccio M, et al. Parathyroid hormone and mobilization of circulating bone marrow-derived cells in uremic patients. J Investig Med. 2011;59(5):823-8.
18. Ballen KK, Shpall EJ, Avigan D, Yeap BY, Fisher DC, McDermott K, et al. Phase I trial of parathyroid hormone to facilitate stem cell mobilization. Biol Blood Marrow Transplant. 2007;13(7):838-43.

19. Adams GB, Martin RP, Alley IR, Chabner KT, Cohen KS, Calvi LM, et al. Therapeutic targeting of a stem cell niche. Nat Biotech. 2007;25(2):238-43.

20. Brunner S, Theiss HD, Murr A, Negele T, Franz W-M. Primary hyperparathyroidism is associated with increased circulating bone marrow-derived progenitor cells. Am J Physiol Endocrinol Metab. 2007;293(6):E1670-5.

21. Ballen K, Mendizabal AM, Cutler C, Politikos I, Jamieson K, Shpall EJ, et al. Phase II trial of parathyroid hormone after double umbilical cord blood transplantation. Biol Blood Marrow Transplant. 2012;18(12):1851-8.

22. Asgharian-Rezaee M, Alipour-Farmad R, Tayarani-Najaran Z. Comparison of Osteogenic Potential of Phenytoin with Dexamethasone in Cultured Dental Pulp Stem Cells. Rep Biochem Mol Biol. 2020;9(3):331-337. 